\title{
HARMONIZING BUSINESS AND DIGITAL ENTERPRISE STRATEGY USING SOA MIDDLE-OUT AND SERVICE-BASED APPROACH
}

\author{
UDC: 339.13:004 \\ 005:004 \\ Original Scientific Paper \\ Zoran DRAGIČEVIĆ ${ }^{1}$, Saša BOŠNJAK ${ }^{2}$ \\ ${ }^{1}$ Kompanija Boksit, 75446 Milići, Trg rudara 1, Republic of Srpska, Bosnia and Herzegovina \\ E-mail: zoran.dragicevic021@ gmail.com \\ ${ }^{2}$ University of Novi Sad, Faculty of Economics in Subotica, 24000 Subotica, Segedinski put 9-11, \\ Republic of Serbia
}

Paper received: 21.05.2019.; Paper accepted: 30.08.2019.

\begin{abstract}
The organization's agility represents its ability to respond fast to changes by the transformation and/or optimization of business processes. In the conditions of the ever-increasing use of digital technologies, the agility of organization can be compromised if the digital strategy and IT resources are not flexible enough to adequately respond to changed business conditions. Service-Oriented Architecture (SOA) promotes better alignment of business goals and IT resources to faster respond to changes. However, given the challenges of the digital era, especially when it comes to distribution, complexity, scalability, and delivery speed, the success of the SOA initiatives increasingly depends on the choice of delivery strategy and implementation approach. The SOA middle-out delivery strategy is guided by business strategy, strategic vision and goals, with reuse of existing IT resources and focus on urgent requirements, tactical and operational goals. On the other hand, SOA evolves towards increasing agility and a simpler, service-based implementation approach that supports fast delivery. This paper, in general, discusses the ways of more efficient alignment of business and digital enterprise strategy, based on the implementation of SOA initiatives for the development of business software systems. Within the framework of the research, the significant challenges and best practices have been identified and clearly distinguished, as well as the advantages and disadvantages, which are related to the key architectural and methodological aspects of the SOA implementation using the middle-out delivery strategy and service-based approach.
\end{abstract}

Keywords: SOA; Business strategy; Digital strategy; Middle-out; Service-based approach; Empirical research.

\section{INTRODUCTION}

The ability to respond fast to changes by business process transformation and/or optimization is a key factor in the competitiveness and growth of organizations in an increasingly competitive environment and market conditions dictated by globalization and the expansion of the use of digital technologies. However, this ability can be compromised if the digital strategy and IT resources are not flexible enough to adequately respond to changed business conditions. Given that dynamic environment, simultaneous changes and reconfiguration of business and IT resources bring significant challenges in defining the business and digital strategy, key factors of harmonization of business and digital strategy are alignment of business and IT resources, and the ability to faster deliver software systems to the production environment (Grover, \& Kohli, 2013; Mithas, Tafti, \& Mitchell, 2013; Yeow, Soh, \& Hansen, 2018).

Service-Oriented Architecture (SOA) is an approach to the design of corporate software solutions that affirm better compliance of business and digital strategy, i.e. business goals and IT resources, enabling the organization and its business partners to adapt more quickly and respond to changes in the business environment. 
On the other hand, SOA as an advanced integration technology (Šereš, \& Tumbas, 2014) provides a platform for easy development and maintenance of integrated systems and applications, and easier harmonization of IT resources with the business model and changing business requirements (Erl, 2007). SOA has significant advantages, like loosely-coupling, scalability, agility, reduced cost, reusability, the composition of services, but security, performance, and management challenges, too (Al-Hamed et al., 2018). Wellimplemented SOA projects directly link IT resources to the business goals of the organization. However, the success of SOA in increasing competitiveness largely depends on the choice of delivery strategy - the way services are identified, as well as the choice of approach in the implementation of SOA.

SOA middle-out delivery strategy is a balanced hybrid approach, i.e. compromise between topdown and bottom-up approach, which at the same time takes the best of both. The application of such a delivery strategy produces both, the compliance of business and information infrastructure with strategic goals, and services suitable for reuse. In the context of such hybrid approach, the effective implementation of SOA can be viewed as a careful balancing and alignment of strategic objectives on the highest level, and immediate, urgent requirements on the tactical and operational level, in a way that supports reuse of services. It also prevents the occurrence of problems that can lead work in the bounded context, due to the lack of consideration of the wider context and the lack of a clear link with the strategic vision and goals. Therefore, work in the bounded context for a longterm result has mainly higher costs of business software solutions (Arsanjani, 2004; Erl, 2007; Kohlborn, Korthaus, Chan, \& Rosemann, 2009; Marks, \& Bell, 2006; Microsoft, 2006; Mirarab, Fard, \& Kenari, 2014; Rosen, Lublinsky, Smith, \& Balcer, 2008; Valipour, Amir Zafari, Maleki, \& Daneshpour, 2009).

On the other hand, the digital era has brought new challenges and demands when it comes to distribution, scaling and increased the complexity and delivery speed of software solutions. This has led to the evolution of the SOA and the emergence of several approaches in the implementation of SOA, which differ in terms of service granularity, resource sharing, integration and service communication, such as ESB (Enterprise Service Bus), service-based approach, microservices, and serverless approach (Ford, Parsons, \& Kua, 2017). Traditional ESB, as a complex integrator and a service orchestrator, usually implemented in the form of a monolithic application, was not designed for the cloud (Taibi, Lenarduzzi, Pahl, \& Janes, 2017; Villamizar et al., 2015). For this reason, in the digital era focus has shifted towards increasing agility and simpler service-based approach at business and technical level, avoiding the complexity of the ESB to allow faster delivery and scaling.

Bearing in mind the new challenges and demands of the digital era, the question arises as of how to align the business and digital strategy in the context of the development of business software systems using the SOA middle-out delivery strategy and service-based approach in the implementation of SOA. In this regard, this paper identifies and addresses the challenges and best practices, as well as significant advantages and disadvantages, related to architectural and methodological aspects in the application of the SOA middle-out and service-based approach in the context of the development of the business software systems.

The paper is organized as follows: Section 2 contains a critical overview of existing knowledge related to service identification and delivery strategies, with a special focus on the middle-out approach, as well as different approaches to SOA implementation, with a special emphasis on service-based approach. Section 3 defines the research questions and describes the applied research method. Section 4 presents the results of a descriptive case study and an exploratory case study. Section 5 gives answers to research questions, with a reference to the transformation of the traditional SOA methodology, identifies potential follow-up research and highlights research limitations. Finally, conclusions are drawn and future works delineated.

\section{BACKGROUND AND RELATED WORK}

The digital strategy connects people, processes and technology (Nahrkhalaji, Shafiee S., Shafiee M., \& Hvam, 2018), with one key difference between the digital strategy and the traditional IT strategy. The traditional IT strategy aims to support the implementation of a business strategy, while the digital strategy can be seen as an IT strategy that tends to become the highest-level business strategy (Sebastian et al., 2017). In this regard, the 
hierarchy is gradually eliminated and the boundary is erased between business and IT strategy, leading to their fusion into a digital strategy (Bharadwaj, El Sawy, Pavlou, \& Venkatraman, 2013). Therefore, the need to align business and IT strategy is increasingly becoming a need to align business and digital strategy. However, aligning business and digital strategy is a bigger challenge because enterprises have a problem when they try to up-front define a digital strategy due to a dynamic environment that requires simultaneous changes and reconfiguration of the various components, not only at the strategic level but also at the level of business and IT resources (Yeow, Soh, \& Hansen, 2018). Therefore, the importance of IT resources in increasing the ability of enterprises to faster deliver software systems to the production environment is particularly emphasized (Grover, \& Kohli, 2013; Mithas, Tafti, \& Mitchell, 2013).

In such a context, SOA promotes better alignment of business goals and IT resources to faster respond to changes and to make sure compliance with business goals when there is a change in business strategy, especially if applications are designed primarily to meet urgent requests or requirements at the tactical level. For that reason, an increase in business-to-technology compliance is seen as one of the key objectives in the implementation of SOA (Erl, 2007). Accordingly, Marks \& Bell (2006) define SOA ,as a conceptual business architecture in which the business functionality or application logic is made available to SOA users or consumers as a shared reusable service available on an IT network. Services in an SOA are modules of business application functionality, with exposed interfaces and are invoked by messages". There are significant challenges in implementation and maintenance of SOA applications, therefore, the success of SOA initiative depends to a large extent on the choice of delivery strategy and the way services are identified, using top-down, bottom-up, meet-inthe-middle (also known as outside-in) or middleout approach (Slimani, Baïna S., \& Baïna K., 2013; Terlouw J., Terlouw L., \& Jansen, 2009). Top-down is an approach driven by a business strategy where services are identified, designed, and implemented on the basis of a detailed analysis of business requirements (Arsanjani, 2004; Erl, 2007; Kohlborn, Korthaus, Chan, \& Rosemann, 2009; Marks \& Bell, 2006). However, the application of this approach often requires too much time, so, when and even if the project is completed, the developed software solution does not meet the new business requirements in an altered business environment (Microsoft, 2006). Therefore, it proved to be impractical, i.e. did not give the desired results (Rosen et al., 2008). In addition, this approach is not suitable if integration with existing systems is necessary, even in the development of trivial software solutions (Zimmermann, Schlimm, Waller, \& Pestel, 2005). The bottom-up approach is based on existing IT resources and driven by IT departments in order to develop reusable services based on existing resources of the organization (Arsanjani, 2004; Erl, 2007; Kohlborn, Korthaus, Chan, \& Rosemann, 2009; Marks \& Bell, 2006; Mirarab, Fard, \& Kenari, 2014; Valipour, Amir Zafari, Maleki, \& Daneshpour, 2009). However, this approach has limited success, because the development of SOA solution without a direct link to the business context and business goals results in a confusing implementation with little relevance to the organization (Microsoft, 2006). In addition, this approach increases the dependence of the service in relation to the existing technological environment (Terlouw J., Terlouw L., \& Jansen, 2009) and creates isolated services that are not suitable for reuse, i.e. do not provide benefit from SOA. The meet-in-the-middle approach involves combining and iterative application of top-down and bottom-up approach (Marks, \& Bell, 2006; Erl, 2007), but existing software systems limit the available options in modeling (Zimmermann et al., 2005), while problems arise when aligning service candidates from the initial top-down phase with created bottom-up services (Terlouw J., Terlouw L., \& Jansen, 2009). The middle-out approach is guided by a strategic vision and business goals, and implemented with several smaller iterative SOA projects, where each individual SOA project is planned and implemented to meet specific business goals and business requirements (Microsoft, 2006). This approach represents a compromise between top-down and bottom-up, as it simultaneously produces both, business and information infrastructure aligned with strategic goals, and reusable services. The key to simultaneous realizing of these two seemingly irreconcilable goals is the SOA reference architecture, also known as the initial or minimal architecture (Rosen et al., 2008). However, need for defining common semantics for services of different types (business, application, domain, utility, integration, basic, external...) makes this approach difficult for the implementation of SOA (Slimani, Baïna S., \& Baïna K., 2013). Regardless 
of the chosen approach to service identification, SOA implementation can be difficult to perform well without the use of an adequate SOA methodology. Most of the existing SOA methodologies support middle-out delivery strategy (Emadi, Jazi, Moghadam, \& Bahredar, 2012; Garo, Russo, \& Tundis 2011; Ramollari, Dranidis, \& Simons, 2007; Rosen et al., 2008).

On the other side, the way of integration and communication between services has a significant impact on the success of the SOA initiative. Due to effective governance is one of the key success factors in the implementation of SOA (Cerny, Donahoo, \& Pechanec, 2017), traditional SOA implementations typically included the use of the ESB. ESB is a universal mediator and an orchestrator in the communication between services of various types, which enables the integration of different applications and technologies with built-in mechanisms for the transformation of messages, registration, monitoring, and service governance (Rademacher, Sachweh, \& Zündorf, 2017; Rosen, Lublinsky, Smith, \& Balcer, 2008). However, the application of the ESB is not a precondition or guarantee for successful implementation of SOA, because the price to be paid is increasing complexity and poor performance (Cerny, Donahoo, \& Pechanec, 2017; Rosen et al., 2008). In the digital era, expansion of digital technologies follows the complexity, distribution, and scalability, as well as the increase in the speed of software delivery (Erder, \& Pureur, 2016). ESB is not designed for the cloud (Taibi, Lenarduzzi, Pahl, \& Janes, 2017; Villamizar et al., 2015). Therefore, it is increasingly criticized as fat, inflexible and difficult to manage (Zimmermann, 2017). A particular problem is the scaling of monolithic applications, where the ESB becomes a bottleneck (Posadas, 2017), which, along with demands for rapid increase in delivery speed, has greatly influenced the evolution of SOA to new implementation approaches, such as service-based approach and microservices (Ford, Parsons, \& Kua, 2017). Bearing in mind that these two approaches are based on direct communication between the services, some researchers mistakenly view them as the same. However, there is a key difference between them; a service-based approach emphasizes the reuse of the services and resources ("share-as-much-as-possible"), while, from other side, microservices are orientated to the concept of a bounded context ("share-nothing" or "share-aslittle-as-possible") (Bogner, Zimmermann, \& Wagner, 2018; Cerny, Donahoo, \& Pechanec,
2017; Ford, Parsons, \& Kua, 2017; Richards, 2016). This is one of the primary reasons why some authors, who come from the agile community, see microservice architecture (MSA) as a new architectural style (Fowler, 2015; Pahl, \& Jamshidi, 2016).

\section{METHODOLOGY}

The first objective of the research is a better understanding of how SOA middle-out delivery strategy and service-based approach can contribute to the harmonization of business and digital strategy in the context of the development of business software systems. The second objective is to identify and address the challenges and best practices, as well as significant advantages and disadvantages related to the architectural and methodological aspects of the software development and delivery process in such a context. In this regard, the following research questions (RQ) were set up:

RQ1: How SOA middle-out delivery strategy and service-based approach can contribute to the harmonization of business and digital strategy?

RQ2: What are the challenges and best practices associated with the application of SOA middle-out and service-based approach?

RQ3: What are the key advantages and disadvantages of implementing SOA middle-out and service-based approach?

To understand better a combination of SOA middle-out delivery strategy and service-based approach, in the context of the development of the business software system using digital technologies, the case study method was applied. In doing so, a descriptive case study is used to better understand the context, the vision of the system and the architectural-methodological aspects of the software development and delivery process. In addition, an exploratory case study is used to identify the challenges, best practices, as well as the advantages and disadvantages of such an approach in a given context. The combination of a descriptive and an exploratory case study aims to better understand the problem in its natural context and define the framework for further research (Runeson, \& Höst, 2009; Yin, 2003).

For the needs of the research, the case of the development of the software system for performance management of business processes 
(hereinafter System) in large, diversified enterprise - Kompanija "Boksit" a.d. Milići (hereinafter Boksit) was selected. After the implementation of the ERP system and Quality Management System (QMS) for standardization needs (ISO, FSC, HACCP), Boksit has identified a need for a more advanced analytical software tool for managing the performance of the business processes. The System is based on the SOA middle-out delivery strategy, service-based approach, and digital technologies, such as analytics, cloud, and mobile in the combined ecosystem. A small, dedicated team consisting of 1 to 3 members, with different levels of competence and experience, has implemented the System. The development of the System has implied the more active role of existing IT resources and new digital technologies in redefining and operationalizing of business strategy, especially in the direction of improvement of business operations, i.e. the way the value is delivered to the customers (Berman, 2012). In this connection, the digital strategy of Boksit was the result of the gradual fusion of business and IT strategy and can be seen as increasing the capacity of existing IT resources and potential application of new digital technologies. Therefore, the digital strategy of Boksit is not hierarchically subordinated and passive in relation to the business strategy, but more proactive, as an integral part of business strategy.

Various data sources, including documents, source code, and semi-structured interview, were used in the data collection process. One of the authors, at different positions in Boksit, was deeply engaged in defining and operationalization of the business and digital strategy, implementation of ERP system and QMS. In addition, as business analyst, software architect and full-stack developer, he played a decisive role in the development of the System, especially in the initial phase, where he developed a functional prototype (Dragičević, 2010), and configured the basic elements of the combined DevSecOps (Development, Security \& Operations) ecosystem, with secured development, test, and production environment. Key research questions were related to the context, motivation, vision of the system, architectural and methodological aspects of the development process and the delivery of the System. Qualitative data were collected in order to better understand the process of development and delivery, and to identify the challenges, best practices, advantages and disadvantages of SOA application middle-out delivery strategy and service-based approach in aligning the business and digital strategy of Boksit. A qualitative analysis has been used to analyze data, because it supports a more detailed description of the observed phenomenon, while qualitative data allow for better insight into the complex processes (Eisenhardt, \& Graebner, 2007). In order to reduce the risk of bias, two authors have carried out the research.

\section{EMPIRICAL RESEARCH RESULTS}

In accordance with the proposed research method, the results of the descriptive case study were presented first. Results describe the implementation of the SOA middle-out delivery strategy and service-based approach in the context of the development of the System in Boksit. After that, the results of the exploratory case study have been presented that identify and address challenges, best practices, as well as the advantages and disadvantages related to architectural and methodological aspects in the application of SOA middle-out delivery strategy and service-based approach in the given context.

\section{Implementation of SOA middle-out delivery strategy and service-based approach}

In this section, the results of a descriptive case study are presented to get the answer to the question: RQ1. How SOA middle-out delivery strategy and service-based approach can contribute to the harmonization of business and digital strategy?

The case study describes the context, the vision of the System, and the key architectural and methodological aspects of the development and delivery process of the software in the combined ecosystem.

\section{Context and vision of the System}

1) Profile - Boksit was founded in 1959. As a three times winner of the award for the most successful company in the Republic of Srpska, it is one of the most important companies in the Republic of Srpska and Bosnia \& Herzegovina. From the classic enterprise for research, production, and preparation of bauxite ore, the company has diversified and developed other business activities, from mining to food production, with more than 800 employees and annual revenues of over 30 million EUR; it operates globally, while the most important markets are the countries of the Western Balkans and the EU. The company is organized on 
the principle of profit centers - production and service divisions, and supporting departments, including IT department.

2) Motivation - Key motivation factors for the development of a software system for performance management of business processes was the improvement of IT resources and operational capabilities in order to more effectively and effectively plan, organize, operationalize and control business processes. Automation of performance management of business processes aimed at more effective operationalization of the business strategy with the improvement of the quality management system, which is based on the requirements of ISO standards, as the basis for continuous monitoring, measurement, and improvement of processes, products, and services.

3) System vision - The System had to provide a detailed insight into key performance indicators (KPIs) of business processes, including the ability to obtain a detailed overview and drill-down options over different periods of time and business analytics, such as employee, organizational unit and partner. The System had to limit access to information in accordance with the positions and the role of users using authentication, authorization, and personalization of content. In addition, the possibility of a future connection of the System with other systems of customers, suppliers, and websites should be foreseen. The System had to utilize the relevant data from the existing ERP system and other records necessary for calculating KPIs of business processes. It was necessary to ensure the daily update of data and logging all the activities of users on the System. The System had to be implemented as an SOA solution, while, for the interaction of users with the System, development of the front-end web application (Web Portal) was envisaged. In the first phase of the development of the System, the priority was building of a functional prototype for KPIs of procurement and sales process, and after that for production, service and support processes. The System had to be open to new functional and non-functional requirements. The conceptual architecture was built to represent the serviceoriented vision of the System at the highest level. It is based on key demands at the highest level of abstraction, in order to identify and build services that are in line with the business and suitable for reuse.

\section{Architectural and methodological aspects of the software development and delivery process}

The process of the System development was based on the SOA methodology proposed by Rosen et al. (2008). The incremental and iterative nature of the development process is noted, where each iteration is treated as a mini SOA project in line with the business strategy, tactics, goals, and priorities. The first iteration was aimed at developing a prototype of minimal functionality. Each of the subsequent iterations, based on the user experience and the selected functional and non-functional requirements of the highest priority for implementation, involved the following activities: 1) identifying the need for redefining business architecture, 2) identifying potential new services, need to remove, divide or merge existing services, 3) design and implementation of new services or modification of the functionality of existing services; 4) adding functionality to the front-end web application with the integration of new/modified services, and 5) the independent delivery of new/changed service and/or a front-end web application in the test environment, and/or the production environment, with the knowledge of user acceptance of the changes. Delivery in the test environment was considered optional, depending on the size and complexity of the increment of functionality.

1) Business Architecture - As the basis for achieving business-IT compliance, business architecture provides a basic overview of the resources and processes of the organization that need to achieve operational, tactical and strategic goals. Building business architecture meant defining the following elements: business motivation model, value chain, and business context diagram. In order to link the key business services to the tactics and business goals of the enterprise at the strategic and tactical level, a business motivational model is used, where the modeling of links between services, business goals, strategies and tactics allowing monitoring of service and business compliance (OMG, 2015). Business services represent IT resources aimed at supporting the implementation of tactics and tactical goals, but also to influence the review of strategy and strategic goals, both at the enterprise level and at the level of profit centers. Presented business motivation model of Boksit (Figure 1) directly links the business service with tactics, strategy and business goals. Based on the process model of the Boksit, a value chain is identified that 
shows the main business processes and their priorities in terms of the importance of creating additional value (Porter, 1985). The value chain of Boksit consists of the realization processes, which include procurement, production and service processes, sales and post-sales services. Finally, the business context diagram is defined as the first step in the business analysis, which enables an understanding of business interaction between actors and systems, as well as the information they exchange.

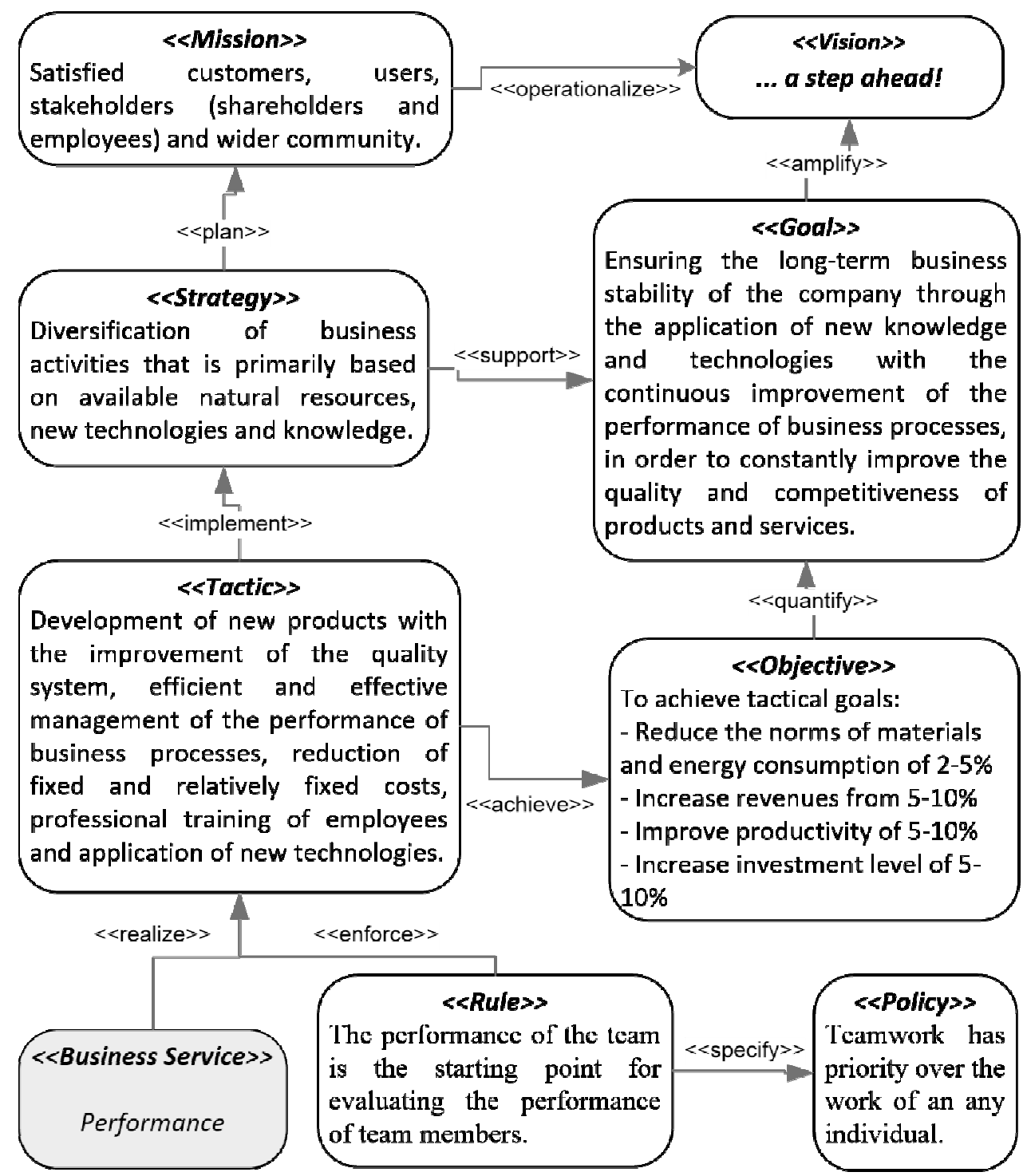

Figure 1: Business motivation model of Boksit

Source: (Dragičević, 2010) adapted by authors

2) Service identification - In order to identify an initial set of potential services, as well as a better understanding of the user-system interaction, a toplevel process model is defined describing the typical user interaction with the system. Based on business requirements, value chain, business context diagrams, and process model, different use cases have been identified. In the context of the enterprise, the security aspects of the solution were examined and the initial service model of the toplevel software solution architecture, the entity model and the information model were defined. Security aspects are considered in the initial SOA implementation iteration because security requirements affect the overall SOA design. User authentication is done on the Web Portal. The Web Portal, as well as the potential systems of customers and suppliers, in the future interactions with the services, must confirm their identity. Authorization is based on the mechanism of roles and rules. The basic rule is that the employee using the system, depending on the roles, has the ability 
only to see own data, data related to the organizational unit it belongs to, as well as to the subordinated organizational units. There is a possibility of defining rules for exceptions, in the direction of the extension these rights, and towards narrowing down these rights. The service model of the top-level software solution architecture determines the granularity of the service and supports the integration of the legacy systems (ERP), business services and front-end web application. The initial service model contains a broader set of services (applications, business, domain, utility, basic and integration) in relation to the conceptual architecture, describing the main responsibilities of individual services and enabling decision-making regarding the inclusion of certain functionalities in the design and implementation of the service. Considering the context of the enterprise, significant attention is paid to identifying common information that will be exchanged between the services. In this regard, the main entities of the business domain are identified, followed by their connections and information exchanged between the service, which will then be declared in the service interfaces.

3) Service interface design - For each service selected for implementation in the current iteration, an interface is designed to include a minimal set of operations and documents, i.e. the parameters passed to the operations, and the result that returns the operations. To minimize dependencies between services, a simple interaction is designed, especially when it comes to domain services and basic services, in order to preserve their huge potential for reuse. The parameters and results of operations are defined in the light of common semantics, with a minimal set of data, avoiding exposure of information that is not needed or which should not be exposed, with the use of naming conventions that simplify and facilitate communication between the services (CoC Convention over Configuration). The granularity of the interface, as well as the granularity of the service, is related directly to the potential of reuse of the service, and it differs depending on the purpose of the service. Application, business, and integration services have the highest granularity, domain services are medium-sized, while utility and basic services are the least granular. In the design of the integration service, the existing functions and data from the ERP system are transformed into new functionalities and information that contribute to the realization of the business strategy and strategic goals. When identifying the need to change the functionality of the service, instead of the versioning, the replacement of the old with the new version of the service is applied, i.e. the old version of the service is discarded, while the new version of the service ensures the functionality for old and new service users.

4) Service design and implementation - Services are designed and implemented in accordance with the design principles proposed by Erl (2007). Each service was developed using WCF, .NET technology, and a 3-tier architectural approach to separate interface, business logic, and access to resources. Any implemented service can be deployed in the test and/or the production environment, independently of other services. The services can be accessed through various communication modes that can realize less or more advanced security mechanism for communicating with other services, which are defined in the configuration file. Business, domain and integration services share a common data source (System Database), while basic services have own data sources using redundant data, which do not share with other services.

\section{5) Implementation of a service-oriented solution -} In order to support reuse of existing services and enable faster and cost-effective development of the business software based on new or changed business requirements, layered $N$-tier solution architecture (Figure 2) is applied. The presentation layer is responsible for adapting the content for a user device, thus making the other layers independent of the device, as well as communicating with the session layer. The session layer is where the System allows multiple interactions with a single user. Services in this layer are responsible for coordinating and managing the user session and session-related user data, authorizing users and applying business rules at the user level, as well as for communicating with the business logic layer. The business logic layer contains the services responsible for the implementation of business logic, domain entities, and for the availability of their functionality through service interfaces. Services from this layer maintain the integrity of shared resources, enforce system business rules, provide a framework and control for transactions, and provide business services for users. The boundary between the session layer and the layer of business logic enables the separation of enterprise resources and resources required to support the user, and 
therefore, better protection and governance of enterprise resources. The resource layer is responsible for managing the shared resources of the enterprise. This layer provides access to shared enterprise resources (data, databases and legacy systems). The Web Portal was developed as an independently deliverable, monolithic web application, based on the application of .NET and Ajax technology, which at the request of the authorized user provides insight into the performance by combining various tabular and graphic parts, allowing drill-down into details. The link between the Web Portal and the business service is realized through the application service Portal, which has the role of a facade, i.e. separating the presentation layer from the business logic layer. Any iteration in the development process required the alignment of the implementation of new functionalities at the level of the Web Portal and the level of individual services, in order to allow the rapid delivery of each subsequent increment of functionality.

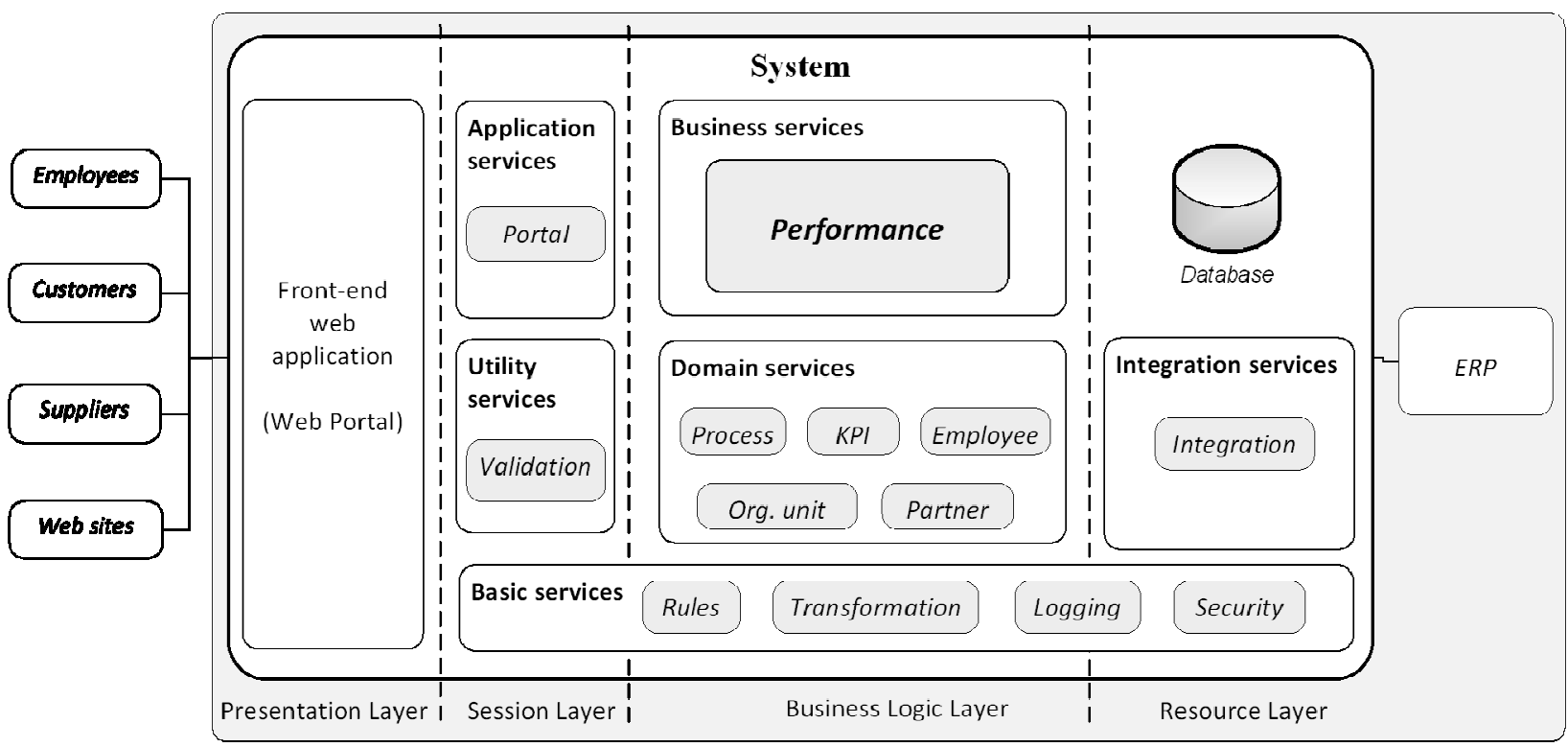

Figure 2: $N$-tier solution architecture

Source: (Dragičević, 2010) adapted by authors

6) Testing, delivery, and monitoring in the combined ecosystem - The combined DevSecOps ecosystem contains development, test, and production environment. Particular attention is paid to security, so the test and production environment is implemented as a private cloud, protected by a firewall, with a Proxy server in the demilitarized zone, while the Web and Database server is behind the firewall in the separated part of the LAN. Scripts and tools were used for delivery, testing, and monitoring. Delivery of services from a development environment in a desired, test or production environment, is realized in two steps: 1) by choosing the appropriate publish profile installation files are generated and 2) by launching the corresponding deploy script simultaneously removing the old one and installing a new version of the services and/or front-end web application, with the simultaneous backup of old and new versions. In the production environment, only one version of the service is active at one point; while the previous versions can be restored at any time using the same deploy script. For monitoring purposes, a tool has been developed that automatically sends e-mail alerts and reports on the realization of scheduled tasks and identified errors.

\section{Challenges and best practices}

This section presents the results of the qualitative analysis of data in order to get the answer to the question: RQ2. What are the challenges and best practices associated with the application of SOA middle-out and service-based approach?

A total of 27 challenges and 27 practices related to the application of SOA middle-out and servicebased approach have been identified and grouped by activities and artifacts of the development and delivery process in the combined ecosystem (Table $1)$. 
Z. Dragičević and Harmonizing business and digital enterprise strategy

Table 1: Challenges and best practices

\begin{tabular}{|c|c|c|c|}
\hline Activity & Artifacts & Challenges & Best practices \\
\hline $\begin{array}{l}\text { Context and } \\
\text { vision of the } \\
\text { system }\end{array}$ & $\begin{array}{l}\text { «document» } \\
\text { - Conceptual architecture of } \\
\text { the system }\end{array}$ & $\begin{array}{l}\text { - Selection of system } \\
\text { implementation strategy } \\
\text { - Defining external system } \\
\text { boundaries } \\
\text { - The flexibility of system } \\
\text { architecture }\end{array}$ & \multirow{2}{*}{$\begin{array}{l}\text { - Lean thinking (timely thinking } \\
\text { and planning) } \\
\text { - Early focus on non-functional } \\
\text { requirements (quality } \\
\text { attributes) } \\
\text { - Continuous, incremental value } \\
\text { delivery } \\
\text { - Minimal documentation }\end{array}$} \\
\hline $\begin{array}{l}\text { Business } \\
\text { architecture }\end{array}$ & $\begin{array}{l}\text { «document» } \\
\text { - Business motivation model } \\
\text { - Value chain } \\
\text { - Business context diagram }\end{array}$ & $\begin{array}{l}\text { - Understanding the context and } \\
\text { interaction of the system and } \\
\text { the environment } \\
\text { - Prioritization of business } \\
\text { processes and activities } \\
\text { - Identification of links between } \\
\text { business and IT resources }\end{array}$ & \\
\hline $\begin{array}{l}\text { Service } \\
\text { identification }\end{array}$ & $\begin{array}{l}\text { «document» } \\
\text { - Model of process } \\
\text { - Use cases } \\
\text { - Service model of the system } \\
\text { architecture } \\
\text { - Types and taxonomy of the } \\
\text { services }\end{array}$ & $\begin{array}{l}\text { - The interdependencies of the } \\
\text { requirements } \\
\text { - Determining the size of a } \\
\text { functional and/or architectural } \\
\text { increment } \\
\text { - Identifying the services that } \\
\text { will implement the increment } \\
\text { of the functionality } \\
\text { - Determining service } \\
\text { granularity } \\
\text { - Identifying shared information } \\
\text { - Enabling service reuse }\end{array}$ & \multirow{4}{*}{ 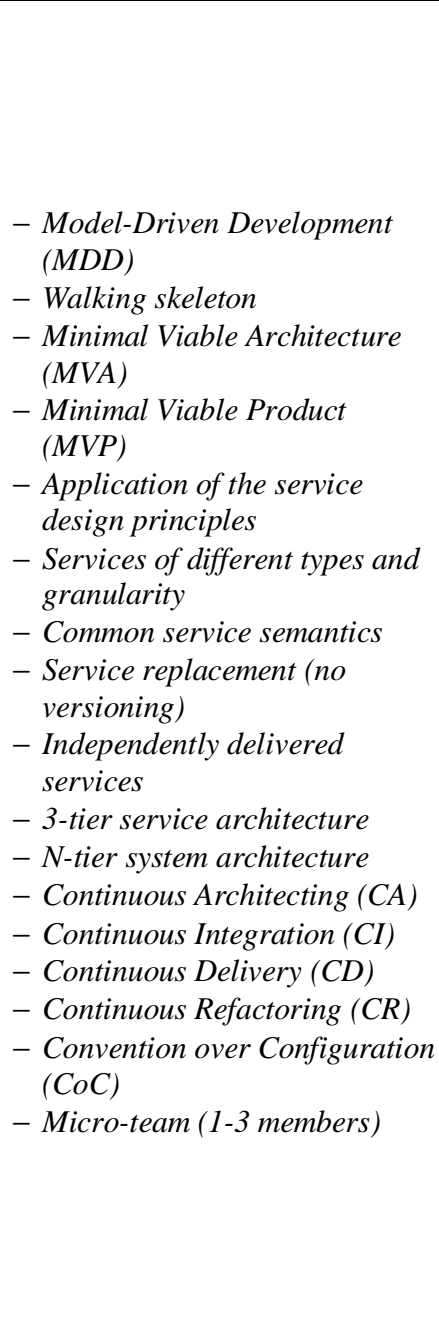 } \\
\hline $\begin{array}{l}\text { Service interface } \\
\text { design }\end{array}$ & $\begin{array}{l}\text { «source code» } \\
\text { - The mode of communication } \\
\text { between the services } \\
\text { - End-points } \\
\text { - Operations } \\
\text { - Documents (parameters and } \\
\text { results of operations) }\end{array}$ & $\begin{array}{l}\text { - Interdependence of services, } \\
\text { especially between business } \\
\text { and integration services } \\
\text { - Choosing the mode of } \\
\text { communication between the } \\
\text { services } \\
\text { - Determining the granularity of } \\
\text { the service interface } \\
\text { - Defining the scope and } \\
\text { visibility of the services } \\
\text { - Choice of approach to service } \\
\text { versioning }\end{array}$ & \\
\hline $\begin{array}{l}\text { Service design } \\
\text { and } \\
\text { implementation }\end{array}$ & $\begin{array}{l}\text { «source code» } \\
\text { - Business rules } \\
\text { - Business logic } \\
\text { - Service local data } \\
\text { - Shared data } \\
\end{array}$ & $\begin{array}{l}\text { - Selecting a type of service } \\
\text { implementation } \\
\text { - Preserving the autonomy of the } \\
\text { services } \\
\text { - Managing shared resources } \\
\end{array}$ & \\
\hline $\begin{array}{l}\text { Implementation } \\
\text { of a service- } \\
\text { oriented solution }\end{array}$ & $\begin{array}{l}\text { «source code» } \\
\text { - Front-end communication } \\
\text { with services } \\
\text { «document» } \\
\text { - Service layout by layers of } \\
\quad N \text {-tier } \text { architecture }\end{array}$ & $\begin{array}{l}\text { - Defining internal system } \\
\text { boundaries } \\
\text { - Deploying services to the } \\
\text { layers of } N \text {-tier system } \\
\text { architecture } \\
\text { - Scalability of the system } \\
\text { - User experience }\end{array}$ & \\
\hline $\begin{array}{l}\text { Testing, delivery, } \\
\text { and monitoring } \\
\text { in a combined } \\
\text { ecosystem }\end{array}$ & $\begin{array}{l}\text { «tool» } \\
- \text { Tools and scripts for build, } \\
\text { publish, test and deploy } \\
\text { - } \text { «report» } \\
\text { - Reports of the execution of } \\
\text { scheduled tasks } \\
\text { - Error reports }\end{array}$ & $\begin{array}{l}\text { - Defining and configuring the } \\
\text { development, test, and } \\
\text { production environment in } \\
\text { combined ecosystem } \\
\text { - Effective testing } \\
\text { - Monitoring of services }\end{array}$ & $\begin{array}{l}\text { - DevSecOps ecosystem } \\
\text { - Virtualization } \\
\text { - Private cloud } \\
\text { - Semi-automated testing } \\
\text { - Semi-automated delivery } \\
\text { - Development of tools for } \\
\quad \text { monitoring and error reporting }\end{array}$ \\
\hline
\end{tabular}




\section{Advantages and disadvantages}

This section presents the results of the qualitative analysis of data in order to get the answer to the question: RQ3. What are the key advantages and disadvantages of implementing SOA middle-out and service-based approach?
In total, eight key advantages and seven key disadvantages were identified that are associated with the application of SOA middle-out and service-based approach (Table 2).

Table 2: Advantages and disadvantages

\begin{tabular}{|l|}
\hline \multicolumn{1}{|c}{ Advantages } \\
\hline 1. Better alignment of business and IT resources \\
Direct linking of business services with business strategy, \\
tactics, and goals, identification of services at the enterprise \\
level, as well as iterative approach with small increments and \\
daily deliveries, contribute to increasing the alignment of \\
business and IT resources, i.e. harmonizing business and \\
digital strategy. \\
2. Increasing agility and flexibility \\
The great potential for reuse of application, basic, \\
infrastructure and integration services, due to their autonomy \\
and the possibility of independent delivery, contributes to \\
increasing of agility and flexibility at enterprise level, and \\
software development and delivery process level.
\end{tabular}

\section{Agilization of SOA methodology}

The application of various agile, lean and continuous practices with SOA methodology has made it possible to reduce increments, increase delivery speed to the level of multiple daily software deliverables, and to get faster feedback from users.

\section{Reducing the complexity of the system}

The greater granularity of application, business and integration services prevents an uncontrolled increase in the number of services, which contributes to reducing the complexity of the system architecture.

\section{Increasing ability to scale services}

Independently deliverable services enable easier scaling, both of the individual parts (services) and the system as a whole.

\section{Fewer errors and bugs}

A micro-team with good communication, a service design that supports testing at the service level, small increments and fast deliveries on a daily basis, contribute to reducing the number, significance, and consequence of errors and bugs, and their faster resolution.

\section{Faster delivery of functionality}

Independent service delivery, small increment and fast feedback from the user support faster delivery of expected functionality to users.

\section{Increasing security}

An early focus on quality attributes, including security and personalization, layered architecture and a combined ecosystem with a test and production environment in private cloud, contribute to increasing of system security.

\section{Up-front architecture and design}

The lack of all relevant information, when it comes to expected functionality and user experience in the initial iteration of the development process, increases the risk of identifying and realizing services, or their functionalities, that will require a big refactoring or prove to be unnecessary.

\section{Increased risk of data inconsistency}

Data redundancy contributes to an increase in service autonomy; however, redundancy of data, with service delivery at short time intervals and distributed transactions, increases the risk of inconsistency in the data.

\section{Poor user experience}

Multiple daily deliveries to production environment lead to frequent interruptions of the current sessions or user activities that have a negative impact on the user experience in working with the system. On the other hand, the number of users affected by service delivery depends directly upon the scope, visibility, and granularity of the delivered services, while the delivery of monolithic front-end web application can affect all active users.

\section{Shared resource scaling problem}

Shared resources, and in particular shared SQL databases, are not suitable for scaling.

\section{Lack of competent people}

It is difficult to find and train, and it is even more difficult to retain people with broad knowledge, competencies, and experience, as well as exceptional discipline and professionalism that are necessary for the role of business analysts, architects and/or full-stack developers, given the complexity that adds the combined DevSecOps ecosystem. The lack of competent people has a negative impact on the ability of the team scaling.

\section{Redundancy of data}

More discipline is needed in order to preserve the consistency of the entire system due to redundant data.

\section{Difficult testing of the whole system}

Increase in a number of services, frequent changes of the interfaces and replacement of services with discarding old versions make it more difficult to test the entire system. 


\section{DISCUSSION}

This section provides answers to research questions, with a reference to the transformation of the applied traditional SOA methodology, which is motivated by the increase in the speed of software delivery. After that, the possibilities for further research and the limitations of the conducted research are presented.

\section{Answers to research questions:}

The results of the research indicate that, in order to harmonize business and digital strategy of the enterprise in the context of the development of a business software system, it is possible to successfully apply the SOA middle-out and service-based approach by combining 1) the traditional SOA methodology that supports middle-out delivery strategy (Rosen et al., 2008), 2) services of different type and granularity, 3) the appropriate practices of agile architecture (Dragičević, \& Bošnjak, 2019), and 4) DevSecOps combined ecosystem, in a way that simultaneously supports reuse of services and fast, even multiple daily, delivery of services and/or front-end web application. Besides, a special focus was on the first iteration, which is based on the initial context and vision of the system, as well as the initial business architecture and service model that produces the initial software architecture (walking skeleton) and functional prototype. In each subsequent iteration, using as small as possible increments, new/changed services and/or front-end web applications with new or modified functionality were delivered fast with fast user feedback.

However, the described approach is not easy to implement, which best illustrates the 27 identified challenges associated with the different activities of the development and delivery process in the combined ecosystem. Overcoming these challenges required the implementation of 27 identified practices of agile architecture in the combined ecosystem, that enable fast simultaneous incremental delivery of required functionality, and to provide an agile, decentralized, resilient architecture that supports reuse of services. The described approach has its advantages and disadvantages. The key identified advantages are better compliance of business and IT resources and faster delivery of functionality as key factors for the alignment of business and digital strategy, which is in line with the results of Yeow, Soh and
Hansen (2018), Grover and Kohli (2013), and Mithas, Tafti and Mitchell (2013). Other identified advantages are increasing agility and flexibility both at the enterprise level and at the level of the development process, reducing the complexity and number of errors and increasing the security and potential for service scaling. On the other hand, a key disadvantage of this approach is a lack of competent, experienced people who can successfully take on multiple roles, from business analysts, through the software architect, and to a full-stack developer. In addition, the price to be paid is a significant up-front and a continuous focus on architecture and design, data redundancy and the difficulty of maintaining their consistency, with additional problems in scaling shared resources, as well as poor user experience and difficult testing of the entire system due to frequent deliveries of modified/new services and/or frontend web application in the combined ecosystem.

\section{Transformation of traditional SOA methodology:}

Development of a service-oriented software system is based on the existing traditional SOA methodology (Rosen et al., 2008). However, differences in the realization of certain activities are identified, especially considering fact that the used SOA methodology was presented before the emergence of Continuous Delivery (CD) practice in 2010, and an expansion of the use of digital technologies, which caused an increase of speed of software delivery. In this regard, the following key differences are noted concerning the approach proposed by Rosen et al. (2008):

- Continuously and timely thinking and planning, instead of up-front plans for defining priorities and software architecture design.

- Minimal documentation and increased use of source code as a source of documentation, which includes interfaces and service operations, semantic information model, service inventory and service architecture.

- Micro-team responsible for the complete life cycle of the service and software system, with broad competencies of team members, who can simultaneously realize multiple roles, from business analysts, software architect, to the fullstack developer, instead of a large team of specialists in many different fields.

- Agilized SOA methodology with the application of various agile, lean and continuous practices, instead of the traditional SOA methodology. 
- Independently delivered services, fast delivery, and user feedback, instead of monolith application.

- Replacing the services, instead of versioning the services.

- The simple DevSecOps ecosystem, supported by scripts and tools for semi-automated testing, delivery, and monitoring, instead of a complex production middleware that supports ESB service orchestration and automation of business processes.

\section{Opportunities for further follow-up research:}

Realized research is based on the single case of the development of a business software system in one company, so additional empirical researches are proposed at the successful and unsuccessful implementation of SOA middle-out and servicebased approach in the digital era. Given that there is no consensus on how to use existing agile methods and practices in the development of service-oriented systems (Carvalho, \& Azevedo, 2013); further research should be done regarding the possible positive impact of agile, lean and continuous principles, methods, techniques and practices on the transformation of traditional SOA methodologies for the development of business software systems. Bearing in mind the perceived disadvantages of SOA middle-out and servicebased approach, future research should identify possibilities for overcoming them by integrating microservices and a service-based approach in the context of the development of business software systems.

\section{Research limitations:}

There are three limitations of the research to be taken into account. First, the research is based on a specific example of the development of business software in just one company; therefore, two separate case studies were conducted - first a descriptive case study, in order to describe in detail and better understand the observed phenomenon in its natural environment, and then exploratory case study, in order to identify the challenges, practices, advantages and disadvantages of the applied architectural-methodological approach, and identify the possibilities for further research. Second, one of the authors, in various positions in Boksit, played roles both, in defining business and digital strategy, as well as in implementing System. Therefore, in order to reduce the risk of bias, more authors are involved in the planning and implementation of the research. Third, the research is based exclusively on qualitative data; therefore, for the needs of qualitative analysis, various sources of qualitative data, including documents, source code and semi-structured interview, have been used.

\section{CONCLUSIONS}

The paper presents the results of empirical research that describes the key architectural and methodological aspects of the implementation of SOA middle-out delivery strategy and servicebased approach in the context of business software system development, as well as identified challenges, best practices, the advantages and disadvantages of such an approach.

The results of the research indicate that the effective implementation of SOA middle-out delivery strategy and service-based approach can contribute to the harmonization of business and digital enterprise strategy. Results confirm that SOA middle-out delivery strategy supports aligning business and IT resources, and that service-based approach increases the ability for faster, multiple daily software delivery in the production environment. Implementation of SOA middle-out delivery strategy and service-based approach is a good opportunity to define, revise and harmonize business and digital strategy, to redefine strategic and/or tactical goals, and to build or improve the business architecture. It is an evolutionary process, which starts with a better understanding of the context, based on existing business and IT resources, in order to upgrade them iteratively. The result of this process is building new IT resources and extending the functionality of existing ones, adding new value to them, avoiding duplication of responsibility and inconsistency. To do all this, business architecture and the service design process must be mutually supportive and coordinated, so there must be a clear link indicating that the resulting business architecture elements directly support the design of the services. Starting from vision, business strategy, strategic goals, and business resources, on the one hand, and digital strategy and IT resources, on the other hand, through key business processes in the value chain, we can identify desired functionalities, services, business entities and the information by which these functionalities are implemented. 
However, the results show that the described approach has significant challenges in all activities of the software development and delivery process. The results also indicate that it is necessary to transform (agilize) traditional SOA methodology by applying many of identified agile architecture implementation practices to simultaneously (1) align business and IT resources, and (2) enable fast, even multiple daily deliveries of software. Identified advantages of such approach are better alignment of business and IT resources, increased agility, flexibility, scalability and security, reduced complexity, errors and bugs, agilized SOA methodology and rapid delivery of functionality, in order to respond faster, more efficiently and more effectively to the changing business environment in the digital era. However, such an approach has significant disadvantages, too. Identified disadvantages include increased the need for upfront focus on architecture and design, risk of poor user experience, shared resource scaling problem, lack of competent people, increased risk of data redundancy and inconsistency, difficulties in testing the system as a whole.

Research contributions are a better understanding of the relationship between business and digital strategy in the context of SOA implementation, identified challenges and best practices, as well as the identified advantages and disadvantages, related to the architectural and methodological aspects of the implementation of the SOA middleout delivery strategy and service-based approach. The findings will contribute to the discussion of the evolution of SOA in the digital era toward increasing agility and reduction of complexity, in order to more effectively align business and digital strategy, and help practitioners to more effectively implement SOA initiatives. Future research should focus on additional empirical research related to the application of SOA middle-out and servicebased approach in the digital era, including a transformation of traditional SOA methodologies using an agile approach. Besides, future research should aim toward identifying the possibilities of combining microservices and service-based approach in the context of the development of business software systems, to overcome identified disadvantages.

\section{REFERENCES}

Al-Hamed, F., Al-Doweesh, S., Al-Omar, R., AlDoweesh, W., \& Najjar, A. (2018). Service Oriented Software Engineering (SOSE): A Survey and Gap
Analysis. In 2018 21st Saudi Computer Society National Computer Conference (NCC) (pp. 1-6). IEEE.

Arsanjani, A. (2004). Service-oriented modeling and architecture. IBM developer works, (January), 1-15.

Berman, S. J. (2012). Digital transformation: opportunities to create new business models. Strategy \& Leadership, 40(2), 16-24.

Bharadwaj, A., El Sawy, O. A., Pavlou, P. A., \& Venkatraman, N. (2013). Digital business strategy: toward a next generation of insights. MIS Quarterly, 471-482.

Bogner, J., Zimmermann, A. \& Wagner, S. (2018). Analyzing the Relevance of SOA Patterns for Microservice-Based Systems, Zeus 2018, 9(February), 9-16.

Carvalho, F., \& Azevedo, L. G. (2013). Service agile development using XP. In 2013 IEEE Seventh International Symposium on Service-Oriented System Engineering (pp. 254-259). IEEE.

Cerny, T., Donahoo, M. J., \& Pechanec, J. (2017). Disambiguation and Comparison of SOA, Microservices and Self-Contained Systems. In Proceedings of the International Conference on Research in Adaptive and Convergent Systems (pp. 228-235). ACM.

Dragičević, Z. (2010). Implementation of SOA using .NET and Ajax technologies (Unpublished master's thesis), Faculty of Economics, Subotica, Serbia. Implementacija SOA korišćenjem tehnologija .NET $i$ Ajax, (neobjavljeni magistarski rad) Ekonomski fakultet u Subotici, Srbija [in Serbian].

Dragičević, Z., \& Bošnjak, S. (2019). Agile architecture in the digital era: Trends and practices. Strategic Management, 24(2), 12-33.

Eisenhardt, K. M., \& Graebner, M. E. (2007). Theory building from cases: Opportunities and challenges. Academy of management journal, 50(1), 25-32.

Emadi, M., Jazi, M. D., Moghadam, R. A., \& Bahredar, F. (2012). An improved methodology for service oriented architecture. In 2012 IEEE International Conference on Computer Science and Automation Engineering (CSAE) (Vol. 2, pp. 350-354). IEEE.

Erder, M., \& Pureur, P. (2016). What's the Architect's Role in an Agile, Cloud-Centric World? IEEE Software, 33(5), 30-33.

Erl, T. (2007). SOA: Principles of Service Design, (Vol. 1). Upper Saddle River: Prentice Hall.

Ford, N., Parsons, R. \& Kua, P. (2017). Building Evolutionary Architectures: supporting constant change. O'Reilly Media, Inc.

Fowler, M. (2015). Microservice Trade-Offs. Retrieved January 18, 2018 from:

https://martinfowler.com/articles/microservice-tradeoffs.html

Garro, A., Russo, W., \& Tundis, A. (2011). Developing Service-Oriented Applications: a method engineering based approach. In Proceedings of the International Conference on Semantic Web and Web Services (SWWS) (p. 1). The Steering Committee of 
The World Congress in Computer Science, Computer Engineering and Applied Computing (WorldComp).

Grover, V., \& Kohli, R. (2013). Revealing your hand: caveats in implementing digital business strategy. MIS Quarterly, 655-662.

Kohlborn, T., Korthaus, A., Chan, T., \& Rosemann, M (2009). Identification and analysis of business and software services - a consolidated approach. IEEE Transactions on Services Computing, 2(1), 50-64.

Marks, E. \& Bell, M. (2006). Service-Oriented Architecture: A Planning and Implementation Guide for Business and Technology Service-Oriented Architecture. John Wiley \& Sons.

Microsoft. (2006). Enabling 'Real World SOA' through the Microsoft Platform. Retrieved March 15, 2018 from: https://www.brightts.com/course/downloads/1.pdf

Mirarab A., Fard N. G. \& Kenari, A. (2014). A New Framework for Service Identification in SOA. Global Journal of Computer Science and Technology, 14(5).

Mithas, S., Tafti, A., \& Mitchell, W. (2013). How a firm's competitive environment and digital strategic posture influence digital business strategy. MIS Quarterly, 511-536.

Nahrkhalaji, S. S., Shafiee, S., Shafiee, M., \& Hvam, L. (2018). Challenges of Digital Transformation: The case of the Non-Profit Sector. In 2018 IEEE International Conference on Industrial Engineering and Engineering Management (IEEM) (pp. 12451249). IEEE.

OMG (2015). Business Motivation Models, Object Management Group. Retrieved March 21, 2019 from: https://www.omg.org/spec/BMM/1.3/pdf

Pahl, C., \& Jamshidi, P. (2016). Microservices: A Systematic Mapping Study. In CLOSER (1) (pp. 137-146).

Porter, M. E. (1985). Competitive Advantage: Creating and Sustaining Superior Performance. The Free Press.

Posadas, J. V. (2017). Application of mixed distributed software architectures for social-productive projects management in Peru. In 2017 IEEE XXIV

International Conference on Electronics, Electrical Engineering and Computing (INTERCON) (pp. 1-4). IEEE.

Rademacher, F., Sachweh, S., \& Zündorf, A. (2017). Differences between model-driven development of service-oriented and microservice architecture. In 2017 IEEE International Conference on Software Architecture Workshops (ICSAW) (pp. 38-45). IEEE.

Ramollari, E., Dranidis, D., \& Simons, A. J. (2007). A survey of service oriented development methodologies. 2nd European Young Researchers Workshop on Service Oriented Computing, Leicester, UK.
Richards, M. (2016). Microservices vs. ServiceOriented Architecture. O'Reilly Media, Inc.

Rosen, M., Lublinsky, B., Smith, K. T. \& Balcer, M. J. (2008). Applied SOA: Service-Oriented Architecture and Design Strategies. Wiley Publishing, Inc.

Runeson, P., \& Höst, M. (2009). Guidelines for conducting and reporting case study research in software engineering. Empirical software engineering, 14(2), 131.

Sebastian, I., Ross, J., Beath, C., Mocker, M., Moloney, K., \& Fonstad, N. (2017). How Big Old Companies Navigate Digital Transformation. MIS Quarterly, (September), 197-213.

Šereš, L. \& Tumbas, P. (2014). ERP \& Globalization: Challenges and Responses. Strategic Management, 19(4), 50-57.

Slimani, S., Baïna, S., \& Baïna, K. (2013).Toward a semantic SOA implementation strategy. In 2013 3rd International Symposium ISKO-Maghreb (pp. 1-4). IEEE.

Taibi, D., Lenarduzzi, V., Pahl, C. \& Janes, A. (2017). Microservices in agile software development. In Proceedings of the XP2017 Scientific Workshops on - XP'17 (pp. 1-5). ACM.

Terlouw, J., Terlouw, L., \& Jansen, S. (2009). An assessment method for selecting an SOA delivery strategy: determining influencing factors and their value weights. In Proceedings of the Busital workshop.

Valipour, M. H., Amir Zafari, B., Maleki, K. N., \& Daneshpour, N. (2009). A brief survey of software architecture concepts and service oriented architecture. In 2009 2nd IEEE International Conference on Computer Science and Information Technology (pp. 34-38). IEEE.

Villamizar, M., Garcés, O., Castro, H., Verano, M., Salamanca, L., Casallas, R., \& Gil, S. (2015). Evaluating the monolithic and the microservice architecture pattern to deploy web applications in the cloud. In 2015 10th Computing Colombian Conference (10CCC) (pp. 583-590). IEEE.

Yeow, A., Soh, C., \& Hansen, R. (2018). Aligning with new digital strategy: A dynamic capabilities approach. The Journal of Strategic Information Systems, 27(1), 43-58.

Yin, R. K. (2003). Case Study Research: Design and Methods. Sage Publications, p. 53.

Zimmermann, O. (2017). Microservices tenets. Computer Science-Research and Development, 32(3-4), 301-310.

Zimmermann, O., Schlimm, N., Waller, G., \& Pestel, M. (2005). Analysis and Design Techniques for Service-Oriented Development and Integration. In GI Jahrestagung (2) (pp. 606-611). 


\section{USKLAĐIVANJE POSLOVNE I DIGITALNE STRATEGIJE PREDUZEĆA PRIMENOM SOA “MIDDLE-OUT" I SERVISNO-BAZIRANOG PRISTUPA}

Agilnost organizacije predstavlja njenu sposobnost da brzo reaguje na promene transformacijom i/ili optimizacijom poslovnih procesa. U uslovima sve bržeg širenja upotrebe digitalnih tehnologija, agilnost organizacije može biti ugrožena ako digitalna strategija i IT resursi nisu dovoljno fleksibilni da adekvatno odgovore na promenjene uslove poslovanja. Servisno-orijentisana arhitektura (SOA) promoviše bolju usklađenost poslovnih ciljeva i IT resursa radi bržeg reagovanja na promene. Međutim, imajući u vidu izazove digitalne ere, posebno kada su u pitanju distribuiranost, kompleksnost, skalabilnost i brzina isporuke, uspeh SOA inicijativa sve više zavisi od izbora strategije isporuke i pristupa u implementaciji SOA. SOA "middle-out" strategija isporuke je vođena poslovnom strategijom, strategijskom vizijom i ciljevima, uz upotrebu postojećih IT resursa i fokusom na hitne zahteve, taktičke i operativne ciljeve. S druge strane, SOA evoluira ka povećanju agilnosti i jednostavnijem, servisno-baziranom pristupu u implementaciji SOA, koji podržava bržu isporuku. Ovaj rad, generalno, razmatra načine za efikasnije usklađivanje poslovne i digitalne strategije preduzeća, bazirane na implementaciji SOA inicijativa za razvoj poslovnih softverskih sistema. U okviru realizovanog istraživanja, identifikovani su i jasno izdvojeni značajni izazovi i dobre prakse, kao i prednosti i mane, koji su vezani za ključne arhitekturalne i metodološke aspekte implementacije SOA primenom "middle-out" strategije isporuke i servisno-baziranog pristupa.

Ključne reči: SOA; Poslovna strategija; Digitalna strategija; Middle-out; Servisno-bazirani pristup; Empirijsko istraživanje. 